\title{
CONSTITUINTES QUÍMICOS DOS FRUTOS DE Copaifera langsdorffii Desf.
}

\author{
José de Sousa Lima Neto \\ Departamento de Química, Universidade Federal do Piauí, 64049-550 Teresina - PI, Brasil \\ Nilce Viana Gramosa* e Edilberto Rocha Silveira \\ Departamento de Química Orgânica e Inorgânica, Centro de Ciências, \\ Universidade Federal do Ceará, CP 6021, 60455-760 Fortaleza - CE, Brasil
}

Recebido em 20/4/07; aceito em 15/2/08; publicado na web em 7/8/08

\begin{abstract}
CHEMICAL CONSTITUENTS OF THE FRUITS OF Copaifera langsdorffii Desf. Phytochemical investigation of the hexane extract of fruit shells of Copaifera langsdorffii Desf. (Caesalpinioideae) afforded ent-kaur-16-en-19-oic acid, polyalthic acid, nivenolide and the mixture of caryophyllene oxide and ent-kaur-16-en-19-oic acid. The chloroform extract of unripe seeds led to the isolation of coumarin and the GC/MS analysis of the extract allowed the identification of $81.8 \%$ of the fatty acid composition after hydrolysis followed by methylation. The main fatty acid identified was oleic acid (33.1\%). The isolation of all secondary metabolites was accomplished by modern chromatographic methods and the structure determination was accomplished by spectrometric methods (IR, MS, NMR ${ }^{1} \mathrm{H}$ and ${ }^{13} \mathrm{C}$ ).
\end{abstract}

Keywords: Copaifera langsdorffi; terpenoids; fatty acids

\section{INTRODUÇÃO}

Copaifera langsdorffii Desf é uma árvore da família Leguminosae (Caesalpinioideae) conhecida popularmente por copaíba, pau-d'óleo, podói, cupaúba e cupiúva. ${ }^{1}$ As plantas do gênero Copaifera encontram-se distribuídas na África e em regiões tropicais e subtropicais da América do Sul principalmente no Brasil, Venezuela, Guianas e Colômbia. No Brasil são encontradas principalmente nos estados do Pará e Amazonas. ${ }^{2}$ Estas plantas fornecem o óleo-resina de copaíba, também conhecido por bálsamo de copaíba, por exsudação do tronco, principalmente de $C$. reticulata (copaíba marimari), $C$. officinalis (copaíba verdadeira) e $C$. langsdorffii (copaíba vermelha), ${ }^{1,-5}$ cujo interesse se deve ao seu variado uso na medicina popular, principalmente como cicatrizante e antiinflamatório. ${ }^{1}$

Embora atualmente sejam descritas 72 espécies de Copaifera, ${ }^{5}$ apenas 17 apresentam registros na literatura sobre seus estudos químicos, em sua maioria referentes ao óleo-resina de $C$. langsdorffii e espécies de Copaifera não identificadas (Copaifera sp). ${ }^{5,6}$

Poucas citações foram encontradas na literatura relacionadas com o fruto da copaíba, sendo destacados os relatos sobre ácidos graxos e cumarinas presentes nas sementes. $\mathrm{O}$ primeiro relato de cumarinas nas sementes foi citado para C. salikuonda Heck, do Sul da África Ocidental. ${ }^{7}$ A presença de compostos cumarínicos de C. langsdorffii foi descrita pela primeira vez por Mors e Monteiro, que obtiveram $0,65 \%$ da cumarina (1) e identificaram a umbeliferona nos extratos etéreos das sementes desta espécie. ${ }^{7}$ A identificação dos ácidos graxos: palmítico $(24,9 \%)$, oleico $(35,3 \%)$, linoleico $(35,7 \%)$, araquídico $(1,1 \%)$ e beênico $(3,0 \%)$ presentes nas sementes de Copaifera $\mathrm{sp}$ foi relatada por Maia et al.. ${ }^{8}$ Nas sementes de C. langsdorffii foram identificados amilóides xiloglucânicos ${ }^{9}$ e nos cotilédones foram encontrados polissacarídeos. ${ }^{10}$

Os estudos químicos e farmacológicos dos óleos essenciais dos frutos e das cascas dos frutos de C. langsdorffii em estudo foram descritos em relatos anteriores. Os constituintes principais identificados para o óleo essencial dos frutos foram: $\gamma$-muuroleno $(29,8 \%)$

\footnotetext{
*e-mail: nilce@dqoi.ufc.br.
}

e $\beta$-cariofileno $(14,8)$, enquanto que para o óleo das cascas dos frutos o constituinte principal era o óxido de cariofileno $(47,3 \%){ }^{6,11}$ As atividades antinociceptiva e antiinflamatória do óleo essencial das cascas dos frutos foram descritas por Paiva et al.. ${ }^{12}$

Embora os relatos da literatura referentes à copaíba mostrem a importância do estudo do óleo-resina devido às propriedades terapêuticas já descritas, é necessário que outras partes da planta sejam avaliadas, com o objetivo de verificar se há semelhança entre as composições químicas do óleo-resina e de outras partes da planta. $\mathrm{O}$ presente trabalho descreveu a metodologia e os resultados obtidos no estudo dos constituintes químicos dos frutos de C. langsdorffii coletados na Chapada do Araripe - Crato - CE.

\section{RESULTADOS E DISCUSSÃO}

O fracionamento cromatográfico das sementes verdes de Copaifera langsdorffii resultou no isolamento de uma substância sólida incolor identificada como cumarina $\mathbf{1}$ através dos dados de IV, RMN e EM e comparação com os dados da literatura. ${ }^{13}$ Segundo Mayer,,${ }^{14}$ esta cumarina é fator importante na dormência das sementes, já que é inibidora natural da germinação. Sendo assim, à medida que a semente amadurece, a cumarina é metabolizada até que o seu teor diminua, favorecendo a quebra da dormência e a germinação das sementes..$^{14,15}$

Os ácidos graxos do extrato clorofórmico das sementes maduras de C. langsdorffii foram identificados a partir da análise por CG-EM dos seus respectivos ésteres metílicos obtidos por metilação com diazometano. ${ }^{11} \mathrm{O}$ cromatograma apresentou 18 picos, cujos espectros de massa foram comparados com os espectros de massa fornecidos pelo banco de dados do equipamento e por comparação visual com espectros de massa encontrados na literatura, ${ }^{16}$ resultando na identificação de 11 ácidos graxos, 81,8\% do total (Tabela 1).

O ácido graxo insaturado 9,12-octadecadienóico (ác. linoleico) descrito na literatura mostrou ser mais abundante para as sementes de Copaifera sp $(35,7 \%)^{8}$ que para as sementes de C. langsdorffii $(2,6 \%)$ neste estudo, enquanto que os teores dos ácidos hexadecanóico (20,2\%) e 9-octadecenóico $(33,1 \%)$ de C. langsdorffii apresentaramse compatíveis com os descritos na literatura para Copaifera sp: 24,9 
Tabela 1. Composição dos ácidos graxos do extrato clorofórmico das sementes de $C$. langsdorffii

\begin{tabular}{|c|c|c|}
\hline Ácido graxo & $\begin{array}{l}\text { Tempo de } \\
\text { retenção }\end{array}$ & $\begin{array}{c}\text { Percentagem } \\
(\%)\end{array}$ \\
\hline octanóico (caprílico C8:0) & 7,7 & 1,9 \\
\hline decanóico (cáprico C10:0) & 9,5 & 1,8 \\
\hline hexadecanóico (palmítico C16:0) & 14,9 & 20,2 \\
\hline 9,12-octadecadienóico (linoleico C18:2) & 16,8 & 2,6 \\
\hline 9-octadecenóico (oleico C18:1) & 17,0 & 33,1 \\
\hline octadecanóico (esteárico C18:0) & 17,3 & 7,0 \\
\hline cis-11-eicosenóico (gôndico C20:1) & 19,1 & 1,7 \\
\hline eicosanóico (araquídico C20:0) & 19,5 & 2,7 \\
\hline docosanóico (beênico C22:0) & 21,5 & 3,6 \\
\hline tetracosanóico (lignocérico C24:0) & 23,4 & 5,7 \\
\hline hexacosanóico (cerótico C26:0) & 25,2 & 1,5 \\
\hline Total & - & 81,8 \\
\hline
\end{tabular}

aTempo de retenção (min) em coluna OV-5

e $35,3 \%$, respectivamente.

O fracionamento cromatográfico do extrato hexânico das cascas dos frutos de $C$. langsdorffii resultou no isolamento e identificação de três ácidos diterpênicos: ácido caurenóico 2 , ácido poliáltico 3 e nivenolídeo 4, bem como da mistura do ácido caurenóico e óxido de cariofileno.

$\mathrm{O}$ espectro de $\mathrm{RMN}{ }^{1} \mathrm{H}$ de 2 apresentou um singleto largo em $\delta_{\mathrm{H}}$ 2,64 $(1 \mathrm{H})$ indicativo de hidrogênio alílico, ligado ao carbono C-13, característico de diterpenos de esqueleto do tipo caureno. Este tipo estrutural foi confirmado pelos sinais característicos dos hidrogênios: $\mathrm{H}-18\left(\delta_{\mathrm{H}} 1,24 ; \mathrm{s} ; 3 \mathrm{H}\right), \mathrm{H}-20\left(\delta_{\mathrm{H}} 0,90 ; \mathrm{s} ; 3 \mathrm{H}\right), \mathrm{H}-17\left(\delta_{\mathrm{H}} 4,80 ; \mathrm{s} ; 1 \mathrm{H}\right)$ e $\mathrm{H}-17\left(\delta_{\mathrm{H}} 4,74 ; \mathrm{s} ; 1 \mathrm{H}\right)$.

No espectro de $\mathrm{RMN}{ }^{13} \mathrm{C}$ de 2 o sinal em $\delta_{\mathrm{C}} 184,9$ foi relacionado ao grupo carboxila e os sinais em $\delta_{C} 156,2$ e 103,5 permitiram confirmar a presença da ligação dupla exocíclica do esqueleto caureno. Os dados obtidos por RMN de $\mathbf{2}$ mostraram-se de acordo com os dados registrados na literatura para o ácido caurenóico, citado como um dos principais constituintes do óleo-resina de copaíba. ${ }^{17}$

No espectro de $\mathrm{RMN}{ }^{1} \mathrm{H}$ de $\mathbf{3}$, três singletos característicos de anel furânico monossubstituído foram observados em $\delta_{\mathrm{H}} 7,35(\mathrm{H}-$ 15); 7,21(H-16) e 6,27(H-14). Os sinais em $\delta_{H} 4,89$ e 4,61 foram relacionados com hidrogênios metilidenos da ligação dupla exocíclica (H-17). O espectro de RMN ${ }^{13} \mathrm{C}$ de 3 mostrou um sinal em $\delta 185,4$, característico de carboxila, além dos sinais em $\delta 148,1 ; 125,8$ e 107,4 evidenciando a presença de anel furânico $\beta$-monossubstituído.

Com os dados obtidos e comparação com dados da literatura ${ }^{18}$ foi possível propor que $\mathbf{3}$ se tratava de um diterpeno furânico de esqueleto labdano conhecido como ácido poliáltico, já isolado de outras espécies de Copaifera. ${ }^{19,20}$

$\mathrm{O}$ espectro de $\mathrm{RMN}{ }^{1} \mathrm{H}$ de 4 mostrou dois singletos em $\delta$ 4,91 e 4,63 relacionados aos hidrogênios metilidênicos (H-17) da ligação dupla exocíclica, bem como, os singletos em $\delta 1,18$ e 0,75 , relativos aos hidrogênios metílicos H-19 e H-20, respectivamente, característicos de esqueleto labdânico. Os sinais em $\delta$ 7,12 (1H) e 4,80 (2H), foram atribuídos aos hidrogênios H-14 e H-15 de um butenolídeo $\alpha$-substituído. Comparação dos dados obtidos com os dados da literatura relatados para o óleo-resina de copaíba ${ }^{6}$ permitiu a caracterização deste composto como o nivenolídeo $4 .^{21}$

Relatos anteriores para o gênero Copaifera mostraram que os ácidos diterpênicos caurenóico, poliáltico e nivenolídeo, bem como o sesquiterpeno óxido de cariofileno são constituintes do óleo-resina de copaíba. ${ }^{5,6}$ Este é o primeiro relato destes compostos nas cascas dos frutos do gênero Copaifera.

\section{PARTE EXPERIMENTAL}

\section{Instrumentação e procedimentos experimentais}

Os espectros na região do IV foram obtidos em espectrômetro Perkin Elmer, modelo FT-IR Espectrum 1000 da central analítica do Departamento de Química Orgânica e Inorgânica-UFC utilizando pastilhas de $\mathrm{KBr}$. Os espectros de $\mathrm{RMN}{ }^{1} \mathrm{He} \mathrm{RMN}{ }^{13} \mathrm{C}$ foram obtidos em espectrômetros Brucker Avance DPX - 300 e DRX-500 operando na freqüência de hidrogênio-1 a 300,13 MHz e a 500,13 MHz e na freqüência do carbono a 75,47 MHz e a $125,75 \mathrm{MHz}$, respectivamente. Os experimentos unidimensionais de $\mathrm{RMN}{ }^{13} \mathrm{C}$ foram efetuados sob desacoplamento total de hidrogênios. As amostras foram dissolvidas em $0,5 \mathrm{~mL}$ de $\mathrm{CDCl}_{3}$ e acondicionadas em tubos de RMN de $5 \mathrm{~mm}$. Os deslocamentos químicos $(\delta)$ foram expressos em partes por milhão (ppm) e referenciados para $\mathrm{RMN}{ }^{1} \mathrm{H}$ pelo pico do hidrogênio pertencente à fração de clorofórmio não deuterada $(\delta 7,27)$ e para $R M N{ }^{13} \mathrm{C}$ pelo pico central do tripleto em $\delta 77,0$ do clorofórmio deuterado. $\mathrm{O}$ padrão de hidrogenação dos carbonos em $\mathrm{RMN}{ }^{13} \mathrm{C}$ foi determinado a partir da utilização da técnica DEPT com o ângulo de nutação $(\theta)$ de $135^{\circ}$. Os pontos de fusão foram determinados em aparelho de microdeterminação MQPAF - 301 (Microquímica) provido de placa aquecedora modelo FP - 52 e unidade de controle FP - 5. Os espectros de massa dos ésteres metílicos dos ácidos graxos foram obtidos em espectrômetro de massa Hewlett-Packard, modelo HP - 5971A, acoplado a cromatógrafo gás-líquido, modelo HP - 5890A série II (CGL-EM), provido de coluna capilar DB-5 (dimetilpolissiloxano) com 30,0 m de comprimento; 0,25 mm de diâmetro interno e filme de $0,1 \mu \mathrm{m}$, utilizando um gradiente de aumento de temperatura do injetor de 35 a $180{ }^{\circ} \mathrm{C} / 4{ }^{\circ} \mathrm{C} / \min$ e 180 a $280{ }^{\circ} \mathrm{C} / 20{ }^{\circ} \mathrm{C} / \mathrm{min}$.

As cromatografias de adsorção em coluna foram realizadas em colunas de vidro de comprimentos e diâmetros variados com gel de sílica 60 (0,063-0,200 mm; 70-230 mesh) Vetec como fase estacionária. Para as cromatografias em camada delgada analítica (CCD) foram utilizadas lâminas de vidro contendo gel de sílica $60 \mathrm{GF}_{254}$ Fluka (Kiesegel) com indicador de fluorescência (254 nm). A revelação das placas CCD foi feita pela exposição das mesmas à lâmpada de<smiles>O=c1ccc2ccccc2o1</smiles>

1

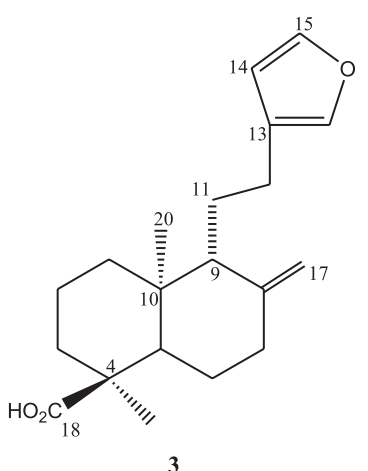

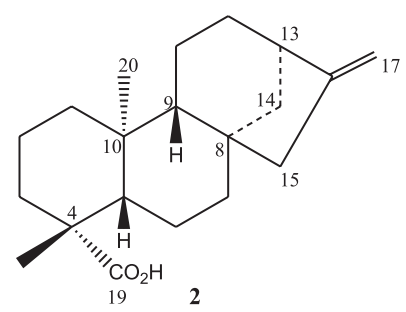

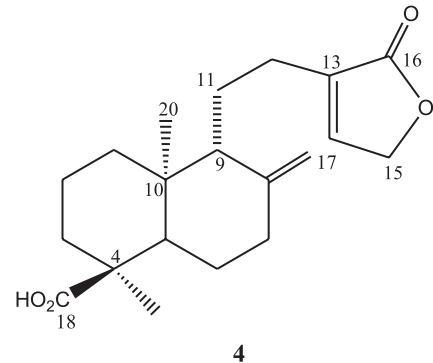

Figura 1. Estruturas das substâncias isoladas dos frutos de Copaifera langsdorffi 
irradiação na faixa do ultravioleta (UV), com dois comprimentos de onda (312 e $365 \mathrm{~nm}$ ). Após pulverização das placas com solução de vanilina e ácido perclórico em etanol, as mesmas foram aquecidas por 5 min em placa aquecedora a aproximadamente $100{ }^{\circ} \mathrm{C}$.

\section{Material vegetal}

Os frutos de Copaifera langsdorffii selecionados para estudo foram coletados na localidade de Barreiro Grande-Crato, Ceará. A exsicata da planta encontra-se depositada no Herbário Prisco Bezerra do Departamento de Biologia da UFC, registrada sob número 24.461.

\section{Extração e isolamento dos constituintes químicos}

As sementes verdes $(469,0 \mathrm{~g})$ de $C$. langsdorffii foram moídas e extraídas com hexano a frio, obtendo-se $11,0 \mathrm{~g}(2,3 \%)$ de uma mistura heterogênea de um óleo amarelo-escuro e um sólido branco que , após recristalização em hexano e filtração, forneceu $1,9 \mathrm{~g}(17 \%)$ de um sólido incolor, identificado como a cumarina 1 [Sólido cristalino incolor, p.f. 67.5-67.7 $\left.{ }^{\circ} \mathrm{C}\right] .{ }^{15}$ As sementes maduras (239 g) forneceram $18,7 \mathrm{~g}(7,8 \%)$ de extrato após terem sido moídas e extraídas com clorofórmio por sohxlet. Uma alíquota de $1,0 \mathrm{~g}$ deste extrato foi submetida à hidrólise alcalina com $603 \mathrm{mg}$ de $\mathrm{KOH}$ dissolvidos em $9 \mathrm{~mL}$ de etanol, sob refluxo por $4 \mathrm{~h}$, seguindo a metodologia descrita por Matos. ${ }^{22}$ Os ácidos graxos obtidos $(758 \mathrm{mg}$ ) foram metilados com diazometano, analisados por CGL-EM e identificados a partir da comparação dos espectros de massa de seus respectivos ésteres metílicos com dados da literatura. ${ }^{16}$

As cascas dos frutos $(810 \mathrm{~g})$ secas e moídas foram submetidas à extração com hexano utilizando o aparelho de sohxlet para extração a quente. $\mathrm{O}$ extrato hexânico foi concentrado em evaporador rotatório sob pressão reduzida resultando num extrato amarelo escuro (CFC-H; $175,7 \mathrm{~g} ; 21,7 \%$ ).

Uma alíquota de 162,8 g de CFCH foi fracionada através de coluna filtrante com gel de sílica resultando nas frações: hexânica $(\mathrm{CFCH}-$ $\mathrm{H} ; 36,1 \mathrm{~g} ; 22,2 \%$ ), clorofórmica (CFCH-C; 69,3 g; 42,6\%), acetato (CFCH-A; 43,2 g; 26,5\%) e metanólica (CFCH-M; 3,2 g; 2,0\%). A fração $\mathrm{CFCH}-\mathrm{H}$ foi submetida a tratamento cromatográfico com gel de sílica e eluída inicialmente com hexano, seguido de misturas binárias de hexano:acetato de etila em gradiente de polaridade crescente. As frações obtidas foram reunidas de acordo com suas semelhanças observadas por CCD. A fração 7-8 (360 mg) eluída com hexano foi recromatografada sobre gel de sílica e eluída com os solventes hexano e acetato de etila puros e suas misturas binárias em ordem crescente de polaridade, resultando no isolamento do ácido caurenóico $2(23,5 \mathrm{mg})$ [Sólido cristalino incolor, p.f. $178,1-179,7^{\circ} \mathrm{C}$ ]. A fração 9-10 (200 mg) eluída com hexano:acetato de etila $90: 10$ foi identificada como uma mistura do ácido caurenóico e óxido de cariofileno 5. A fração 16 (300 mg) eluída com hexano:acetato de etila 90:10 foi analisada por $\mathrm{RMN}{ }^{1} \mathrm{H}$ e ${ }^{13} \mathrm{C}$ e caracterizada como o ácido poliáltico 3 [Sólido branco amorfo, p.f. $\left.98,5-99,8^{\circ} \mathrm{C}\right] .{ }^{20}$ Parte da fração CFCH-C $(10 \mathrm{~g})$ foi cromatografada em coluna cromatográfica sobre gel de sílica e eluição isocrática com hexano:acetato de etila 90:10, resultando no isolamento dos diterpenos ácido poliáltico $3(150 \mathrm{mg})$ e nivenolídeo 4 (18 mg) [Sólido branco amorfo]. ${ }^{6}$

\section{AGRADECIMENTOS}

Ao CNPq, FINEP, PRONEX, PADCT e CAPES pelo apoio financeiro e pelas bolsas concedidas. Aos Profs. A. G. Fernandes e E. P. Nunes do Departamento de Biologia da Universidade Federal do Ceará pela identificação botânica da planta.

\section{REFERÊNCIAS}

1. Corrêa, M. P.; Dicionário de plantas úteis do Brasil e das exóticas cultivadas, Imprensa Nacional: Rio de Janeiro, 1984.

2. Willis, J. C.; A Dictionary of flowering plants and ferns, $8^{\text {th }}$ ed., Cambridge Press: Great Britain, 1973.

3. Veiga Jr., V. F.; Patitucci, M. L; Pinto, A. C.; Quim. Nova 1997, 20, 612.

4. Gottlieb, O. R.; Iachan, A.; Revista de Química Industrial 1945, 14, 20 .

5. Veiga Jr., V. F.; Pinto, A. C.; Quim. Nova 2002, 25, 273.

6. Gramosa, N. V.; Tese de Doutorado, Universidade Federal do Ceará, Brasil, 2001.

7. Mors, W. B.; Monteiro, H. J.; Anais da Associação Brasileira de Química 1959, 18, 181.

8. Maia, J. G.; Varejão, M. J. C.; Wolter Filho, W.; Mourão, A. P.; Craveiro, A. A.; Alencar, J. W.; Acta Amazônica 1978, 8, 705.

9. Buckeridge, M. S.; Rocha, D. C.; Reid, J. S. G.; Dietrich, S. M. C.; Physiol. Plant. 1992, 86, 145.

10. Franco, T. T.; Rodrigues, N. R.; Serra, G. E.; Panegassi, V. R.; Buckeridge, M. S.; J. Chromatogr, B: Anal. Technol. Biomed. Life Sci. 1996, 680, 255

11. Gramosa, N. V.; Silveira, E. R.; J. Essent. Oil Res. 2005, 17, 130.

12. Paiva, L. A. F.; Santos, F. A.; Rao, V. S. N.; Silveira, E. R.; Resumos do $14^{\circ}$ Simpósio de Plantas Medicinais do Brasil, Florianópolis, Brasil, 1996.

13. Murray, R. D. H.; Mendez, J.; Brown, S. A.; The Natural Coumarins, Wiley: New York, 1982.

14. Mayer, A. M.; The germination of seeds, $4^{\text {th }}$ ed., Pergamon Press: Great Britain, 1989

15. Borges, E. E. L; Borges, R. D. G.; Candido, J. F.; Gomes, J. M.; Rev. Bras. Sementes 1982, 4, 9.

16. Adams, R. P.; Identification of essential oil components by gas chromatography/ quadrupole mass spectroscopy, Allured Publishing Corporation: Illinois, 2001.

17. Hutchison, M.; Lewer, P.; Macmillan, J.; J. Chem. Soc., Perkin Trans. I 1984, 2363.

18. Carreras, C. R.; Rossomando, P. C.; Giordano, O. S.; Phytochemistry 1998, $48,1031$.

19. Braga, W. F.; Pinto, A. C.; Antunes, O. A. C.; Resumos da 14a Reunião Anual da Sociedade Brasileira de Química, Caxambu, Brasil, 1991.

20. Ferrari, M.; Pagnoni, U. M.; Pelizzoni, F.; Phytochemistry 1971, 10, 905.

21. Rojas, E. T.; Rodriguez-Hahn, L.; Phytochemistry 1978, 17, 574.

22. Matos, F. J. A.; Introdução a Fitoquímica Experimental, Editora UFC: Fortaleza, 1997. 